\title{
Improvement of Aminopeptidase Activity of Dizinc(II) Complexes by Increasing Substrate Accessibility
}

\author{
Md. Jamil Hossain, Akinobu Wada, Yasuhiro Igarashi, Kei-ichiro Aimono, Keisuke Suzuki, \\ Katsuya Tone, and Hiroshi Sakiyama
}

Department of Material and Biological Chemistry, Faculty of Science, Yamagata University, Kojirakawa, Yamagata 990-8560, Japan

Correspondence should be addressed to Hiroshi Sakiyama, saki@sci.kj.yamagata-u.ac.jp

Received 22 November 2010; Accepted 2 March 2011

Academic Editor: Rabindranath Mukherjee

Copyright (C) $2011 \mathrm{Md}$. Jamil Hossain et al. This is an open access article distributed under the Creative Commons Attribution License, which permits unrestricted use, distribution, and reproduction in any medium, provided the original work is properly cited.

A new dizinc(II) complex, $\left[\mathrm{Zn}_{2}(\right.$ bhmp $\left.)\left(\mathrm{MeCO}_{2}\right)_{2}\right] \mathrm{BPh}_{4}\left[(\mathrm{bhmp})^{-}\right.$: 2,6-bis[bis(2-hydroxyethyl)aminomethyl]-4-methylphenolate anion], performs aminopeptidase activity to hydrolyze $L$-leucine-p-nitroanilide. As compared with a related dizinc(II) complex $\left[\mathrm{Zn}_{2}\right.$ (bomp) $\left.\left(\mathrm{MeCO}_{2}\right)_{2}\right] \mathrm{BPh}_{4}\left[(\text { bomp })^{-}: 2,6\right.$-bis[bis(2-methoxyethyl)aminomethyl]-4-methylphenolate anion], the activity of the present bhmp complex was about 80 times greater than that of the bomp complex. This is mainly because the substrate accessibility was improved by changing the terminal methoxy groups to hydroxyl groups.

\section{Introduction}

Aminopeptidases are exopeptidases that remove the $\mathrm{N}$ terminal amino acid from a protein [1-5]. It is interesting that most of the well-characterized aminopeptidases contain dinuclear metal cores at their active sites, while carboxypeptidases, which remove the $C$-terminal amino acid, do not have dinuclear cores. The well-characterized aminopeptidases are leucine aminopeptidase (LAP, EC 3.4.11.1) [1], methionine aminopeptidase (MAP, EC 3.4.11.18) [2], aminopeptidase from Aeromonas proteolytica (AAP, EC 3.4.11.10) [3], Streptomyces griseus aminopeptidase (SGAP, EC 3.4.11.-) [4], and proline aminopeptidase (PAP, EC 3.4.11.9) [5]. LAP, AAP, and SGAP contain dizinc(II) cores at their active sites, while MAP contains a dicobalt(II) core and PAP contains a dimanganese(II) core.

With the intention of finding a minimum functional unit of aminopeptidase, Sakiyama and coworkers developed a dizinc(II) complex which can be represented by the following $\left[\mathrm{Zn}\right.$ (bomp) $\left.\left(\mathrm{MeCO}_{2}\right)_{2}\right] \mathrm{BPh}_{4}$ as the first functional model of aminopeptidase [6] represented by [(bomp $)^{-}: 2,6$-bis[bis (2methoxyethyl)aminomethyl]-4-methylphenolate anion]; later, the aminopeptidase activity was improved by the introduction of stronger electron-withdrawing $p$-substituents [7] (the aminopeptidase activity was improved 10 times for the chloro-substituted complex represented by the following $\left[\mathrm{Zn}_{2}\right.$ (bocp) $\left.\left(\mathrm{MeCO}_{2}\right)_{2}\right] \mathrm{BPh}_{4}$ and was improved 250 times for the nitro-substituted complex represented by the following $\left[\mathrm{Zn}_{2}\right.$ (bonp) $\left.\left(\mathrm{MeCO}_{2}\right)_{2}\right] \mathrm{BPh}_{4}[\text { (bocp) })^{-}$: 4-chloro2,6-bis[bis(2-methoxyethyl)aminomethyl]phenolate anion; (bonp) ${ }^{-}$: 2,6-bis[bis(2-methoxyethyl)aminomethyl]-4-nitrophenolate anion]). From the kinetic studies, the substrate was proved to be incorporated within the dizinc center [7].

On the other hand, we found that the substrate accessibility of the bomp complexes was not good because of the steric hindrance of the terminal methoxy groups [7]. Therefore, in the present study, a new dizinc(II) complex, $\left[\mathrm{Zn}_{2}(\mathrm{bhmp})\left(\mathrm{MeCO}_{2}\right)_{2}\right] \mathrm{BPh}_{4}(\mathbf{1})$, has been synthesized using a dinucleating ligand, bhmp ${ }^{-}\left[(\mathrm{bhmp})^{-}\right.$: 2,6-bis[bis(2hydroxyethyl)aminomethyl]-4-methylphenolate anion] [8], in which the methoxy groups of the bomp ligand are substituted into less-hindered hydroxyl groups, and the aminopeptidase activity of the complex was examined (see Scheme 1).

\section{Experimental}

2.1. Measurements. Elemental analyses were obtained at the Elemental Analysis Service Centre of Kyushu University. 


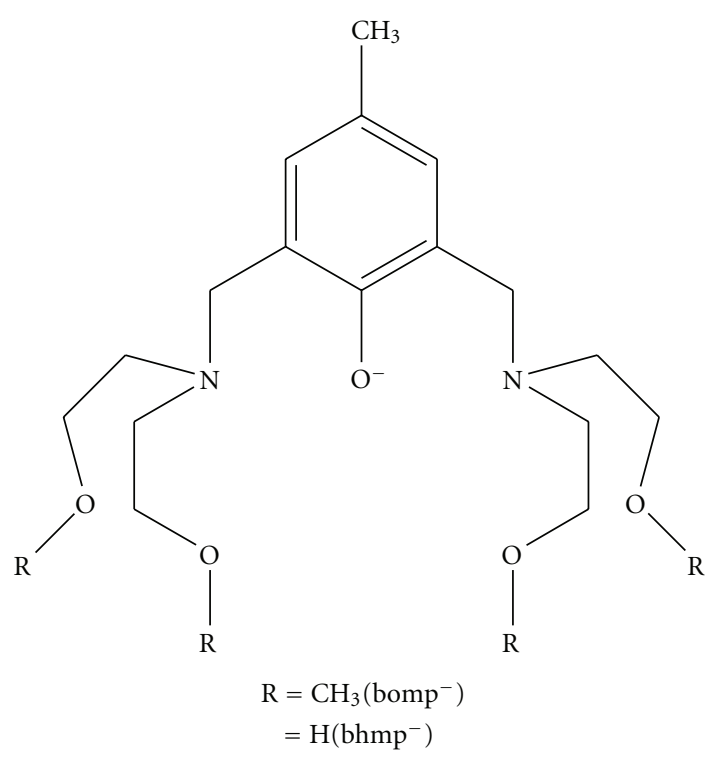

Scheme 1

Infrared (IR) spectra were recorded on a Hitachi 27050 spectrometer. Electronic spectra were recorded on a Shimadzu UV-240 spectrophotometer.

2.2. Materials. $\mathrm{Na}(\mathrm{bhmp})$ was prepared as previously described in [8]. All other chemicals were commercial products and were used as supplied.

2.3. Synthesis of $\left[\mathrm{Zn}_{2}(b h m p)\left(\mathrm{MeCO}_{2}\right)_{2}\right] \mathrm{BPh}_{4} \cdot 2 \mathrm{MeCN}$ (1). To a methanolic solution ( $15 \mathrm{~mL})$ of $\mathrm{Na}$ (bhmp) $(0.19 \mathrm{~g}$, $0.52 \mathrm{mmoL})$ was added $\operatorname{zinc}(\mathrm{II})$ acetate dihydrate $(0.22 \mathrm{~g}$, $1.00 \mathrm{mmoL}$ ), and the resulting solution was refluxed for 1 hour. The addition of sodium tetraphenylborate $(0.17 \mathrm{~g}$, $0.50 \mathrm{mmoL}$ ) resulted in the precipitation of colorless microcrystals, which were recrystallized from acetonitrile. Yield 0.26 g (52\%). (Found: C, 59.15; H, 6.20; N, 5.65; Zn, 14.1. Calc. for $\mathrm{C}_{49} \mathrm{H}_{61} \mathrm{BN}_{4} \mathrm{O}_{9} \mathrm{Zn}_{2}: \mathrm{C}, 59.35 ; \mathrm{H}, 6.20 ; \mathrm{N}, 5.65 ; \mathrm{Zn}$, $13.2 \%)$. Selected IR data $\left[\nu / \mathrm{cm}^{-1}\right]$ using $\mathrm{KBr}$ disk: 3410, 3240, 3050-2850, 1605, 1580, 1475, 1420, 1330, 1260, 1130, 1030, 870, 730, 700, 605 .

2.4. Aminopeptidase Activity. The aminopeptidase activity of the complex was estimated using $l$-leucine- $p$-nitroanilide as a substrate [6]. The substrate was dissolved in $1.5 \mathrm{~mL}$ of a tricine buffer solution ( $\mathrm{pH} \mathrm{8}$ ), and to this was added $1.0 \mathrm{~mL}$ of a DMF solution of the complex at room temperature. The hydrolysis of the substrate into $l$-leucine and $p$-nitroaniline was monitored by detecting the formation of $p$-nitroaniline using a spectrometer at $405 \mathrm{~nm}$. In the measurement, spontaneous hydrolysis of the substrate was subtracted as a background. This measurement was examined at various complex concentrations from 0 to $5.0 \times 10^{-4} \mathrm{~mol} \mathrm{dm}^{-3}$ and at various substrate concentrations from 0 to $5.9 \times 10^{-4} \mathrm{~mol}$ $\mathrm{dm}^{-3}$. This procedure was also carried out at $\mathrm{pH}$ values

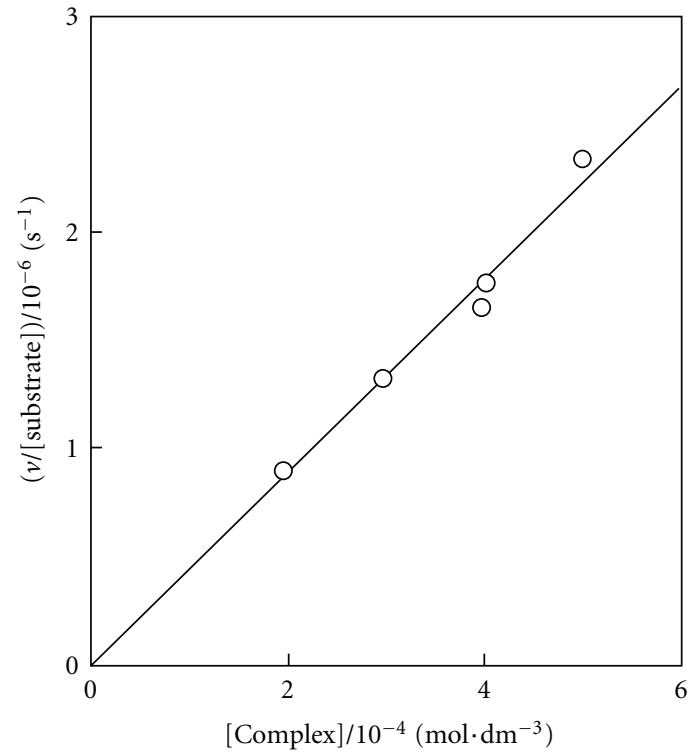

FIgure 1: A $v /$ [substrate] versus [complex] plot in the hydrolysis of $l$-leucine-p-nitroanilide by $\mathbf{1}$ at nominal $\mathrm{pH} 8$.

varying from 7 to 10 using HEPES ( $\mathrm{pH} 7)$, tricine $(\mathrm{pH} \mathrm{8)}$, and CHES ( $\mathrm{pH} 9-10)$ buffers.

\section{Results and Discussion}

3.1. Aminopeptidase Activity at $p H$ 8. Before the discussion about the aminopeptidase activity, it should be noted that simple zinc salts, such as zinc(II) chloride and zinc(II) sulfate, do not show aminopeptidase activity [6]. First, the aminopeptidase activity of complex 1 was estimated in a mixture of $40 \%$ DMF and $60 \%$ aqueous solution at $\mathrm{pH} 8$ using $l$-leucine- $p$-nitroanilide as a substrate. Hereafter, the term "nominal $\mathrm{pH}$ " will be used because the experiments were carried out in a mixture of DMF and water. The measurement was carried out at various complex concentrations and at various substrate concentrations, and the initial rate $v$ was obtained for each experiment. A plot of the initial rate over the substrate concentration $v /$ [substrate] versus the complex concentration [complex] showed good linearity (Figure 1), as did the previous complexes [6, 7, 9], which indicates that the initial rate can be written as a second-order rate equation as follows:

$$
v=k[\text { substrate }][\text { complex }],
$$

where $k$ is the second-order rate constant. The $k$ value for the bhmp complex 1 was calculated as 4.4(2) $\times$ $10^{-3} \mathrm{dm}^{3} \mathrm{~mol}^{-1} \mathrm{~s}^{-1}$. The previously obtained $k$ value for the bomp complex was $2.3(1) \times 10^{-3} \mathrm{dm}^{3} \mathrm{~mol}^{-1} \mathrm{~s}^{-1}$ under the same conditions [6]. Therefore, the rate for 1 was about two times greater than that for the bomp complex at nominal $\mathrm{pH}$ 8.

3.2. Effect of $p H$ on the Aminopeptidase Function. The above procedure was also carried out at nominal pH's varying from 


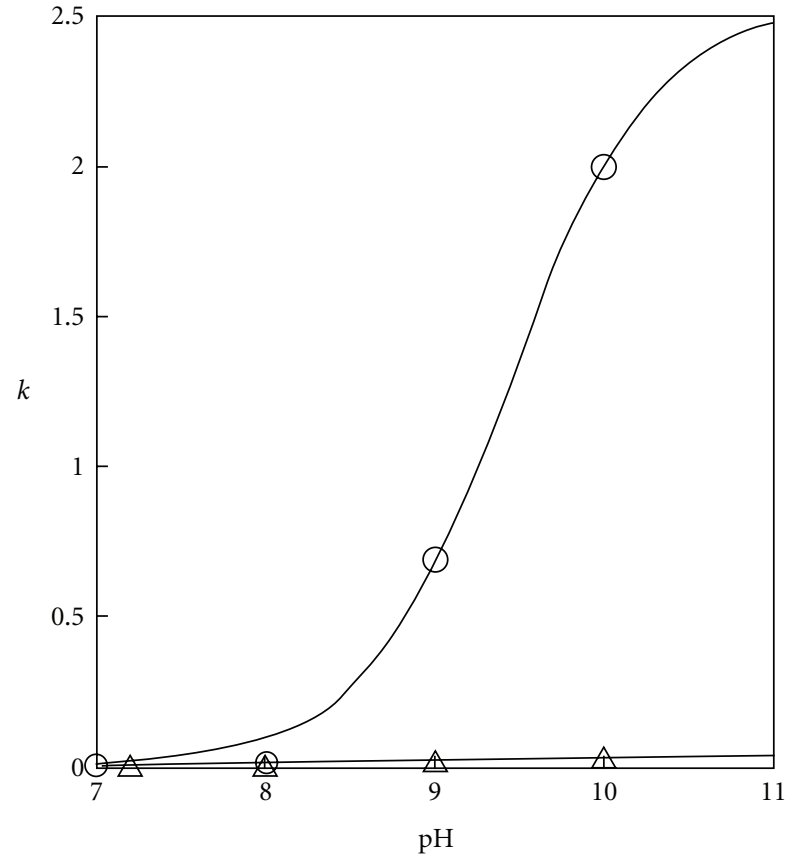

FIgURE 2: $k$ versus nominal $\mathrm{pH}$ plots for the bhmp complex $1(\mathrm{O})$ and the previous bomp complex $(\triangle)$. The curves are drawn by $(2)$ using the parameters in the text.

7 to 10 . At nominal $\mathrm{pH} 7$, the activity was too small to determine the rate constant, but in the nominal $\mathrm{pH}$ range from 8 to 10 , the second-order rate equation was found to be valid. The $k$ versus nominal $\mathrm{pH}$ plot for $\mathbf{1}$ is shown in Figure 2. The plot is sigmoidal around the nominal $\mathrm{pH}$ 9.5, and the data could be fitted using (2) with parameters $k_{\text {depro }}=2.55 \mathrm{dm}^{3} \mathrm{~mol}^{-1} \mathrm{~s}^{-1}$ and $\mathrm{p} K_{\mathrm{a}}=9.44$, where $k_{\text {depro }}$ is the rate constant for the deprotonated form.

$$
k=k_{\text {depro }} \frac{K_{\mathrm{a}}}{K_{\mathrm{a}}+\left[H^{+}\right]} .
$$

The result indicates that the reaction was promoted by the deprotonated form of the complex, which will be discussed in Section 3.3. In the case of the previous bomp complex, the data was reexamined using (2), and the parameters were determined as $k_{\text {depro }}=3.26 \times 10^{-2} \mathrm{dm}^{3} \mathrm{~mol}^{-1} \mathrm{~s}^{-1}$ and $\mathrm{p} K_{\mathrm{a}}=9.07$. The activity $\left(k_{\text {depro }}\right)$ of the present bhmp complex 1 was about 80 times greater than that of the bomp complex although the $k$ value at nominal $\mathrm{pH} 8$ was about only 2 times greater. This is because the pKa value of $\mathbf{1}$ is slightly larger than that of the bomp complex.

3.3. Some Considerations about the Active Species. According to the crystal structure of related cobalt(II) complex $\left[\mathrm{Co}_{2}(\mathrm{bhmp})\left(\mathrm{MeCO}_{2}\right)_{2}\right] \mathrm{BPh}_{4}[8]$, the coordination geometry around each zinc(II) ion is saturated, and the two zinc(II) ions are bridged by two acetate ions. However, the dissociation of the acetate ions occurs rather easily in an aqueous solution, affording vacant coordination sites for substrate incorporation. Indeed, in the cases of related cobalt(II) and nickel(II) complexes, $\left[\mathrm{Co}_{2}(\mathrm{bhmp})\left(\mathrm{MeCO}_{2}\right)_{2}\right] \mathrm{ClO}_{4}$ and
$\left[\mathrm{Ni}_{2}\right.$ (bhmp) $\left.\left(\mathrm{MeCO}_{2}\right)_{2}\right] \mathrm{ClO}_{4}$, the dominant species in an aqueous solution were identified as $\left[\mathrm{M}_{2}(\mathrm{bhmp})\left(\mathrm{H}_{2} \mathrm{O}\right)_{4}\right]^{2+}$ and $\left[\mathrm{M}_{2}(\mathrm{bhmp})\left(\mathrm{MeCO}_{2}\right)\left(\mathrm{H}_{2} \mathrm{O}\right)_{2}\right]^{+}\left(\mathrm{M}=\mathrm{Co}^{\mathrm{II}}, \mathrm{Ni}^{\mathrm{II}}\right)$ by analyzing the electronic spectra [10]. When one or two water molecules of $\left[\mathrm{Zn}_{2}(\mathrm{bhmp})\left(\mathrm{H}_{2} \mathrm{O}\right)_{4}\right]^{2+}$ are exchanged with the substrate and a remaining water molecule is deprotonated, a nucleophilic $\mathrm{Zn}-\mathrm{OH}$ moiety is thought to attack the carbonyl carbon of the bound substrate.

\section{Conclusion}

For the purpose of improving the substrate accessibility, a new dizinc(II) complex, $\left[\mathrm{Zn}_{2}(\mathrm{bhmp})\left(\mathrm{MeCO}_{2}\right)_{2}\right] \mathrm{BPh}_{4}(\mathbf{1})$, was synthesized, and its aminopeptidase activity was investigated. As compared with the previous dizinc(II) complex, $\left[\mathrm{Zn}_{2}\right.$ (bomp) $\left.\left(\mathrm{MeCO}_{2}\right)_{2}\right] \mathrm{BPh}_{4}$, the activity of $\mathbf{1}$ was about 80 times greater. Routine kinetic results have been deposited as supplementary material at 10.1155/2011/395418.

\section{References}

[1] S. K. Burley, P. R. David, A. Taylor, and W. N. Lipscomb, "Molecular structure of leucine aminopeptidase at $2.7-\AA$ resolution," Proceedings of the National Academy of Sciences of the United States of America, vol. 87, no. 17, pp. 6878-6882, 1990.

[2] S. L. Roderick and B. W. Matthews, "Structure of the cobaltdependent methionine aminopeptidase from escherichia coli: a new type of proteolytic enzyme," Biochemistry, vol. 32, no. 15, pp. 3907-3912, 1993.

[3] B. Chevrier, C. Schalk, H. D’Orchymont, J. M. Rondeau, D. Moras, and C. Tarnus, "Crystal structure of Aeromonas proteolytica aminopeptidase: a prototypical member of the co-catalytic zinc enzyme family," Structure, vol. 2, no. 4, pp. 283-291, 1994.

[4] H. M. Greenblatt, O. Almog, B. Maras et al., "Streptomyces griseus aminopeptidase: X-ray crystallographic structure at $1.75 \AA$ resolution," Journal of Molecular Biology, vol. 265, no. 5, pp. 620-636, 1997.

[5] M. C. J. Wilce, C. S. Bond, N. E. Dixon et al., "Structure and mechanism of a proline-specific aminopeptidase from Escherichia coli," Proceedings of the National Academy of Sciences of the United States of America, vol. 95, no. 7, pp. 34723477, 1998.

[6] H. Sakiyama, R. Mochizuki, A. Sugawara, M. Sakamoto, Y. Nishida, and M. Yamasaki, "Dinuclear zinc(II) complex of a new acyclic phenol-based dinucleating ligand with four methoxyethyl chelating arms: first dizinc model with aminopeptidase function," Journal of the Chemical Society, Dalton Transactions, no. 6, pp. 997-1000, 1999.

[7] H. Sakiyama, Y. Igarashi, Y. Nakayama, M. J. Hossain, K. Unoura, and Y. Nishida, "Aminopeptidase function of dinuclear zinc(II) complexes of phenol-based dinucleating ligands: effect of $p$-substituents," Inorganica Chimica Acta, vol. 351, pp. 256-260, 2003.

[8] M. J. Hossain, M. Yamasaki, M. Mikuriya, A. Kuribayashi, and H. Sakiyama, "Synthesis, structure, and magnetic properties of dinuclear cobalt(II) complexes with a new phenol-based dinucleating ligand with four hydroxyethyl chelating arms," Inorganic Chemistry, vol. 41, no. 15, pp. 4058-4062, 2002. 
[9] H. Sakiyama, K. Ono, T. Suzuki, K. Tone, T. Ueno, and Y. Nishida, "Aminopeptidase function of dinuclear zinc(II) complexes with chiral dinucleating ligands: stereoselectivity by chiral substrate recognition," Inorganic Chemistry Communications, vol. 8, no. 4, pp. 372-374, 2005.

[10] A. Kazama, A. Wada, H. Sakiyama, M. J. Hossain, and Y. Nishida, "Synthesis of water-soluble dinuclear metal complexes $[$ metal $=$ cobalt(II) and nickel(II)] and their behavior in solution," Inorganica Chimica Acta, vol. 361, no. 9-10, pp. 2918-2922, 2008. 


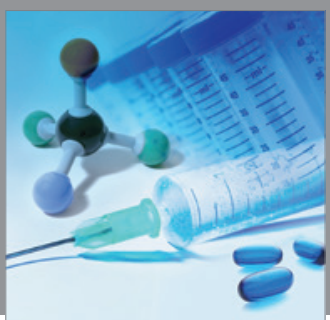

International Journal of

Medicinal Chemistry

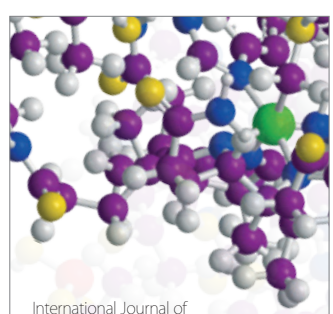

Carbohydrate Chemistry

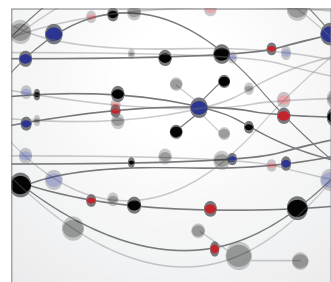

The Scientific World Journal
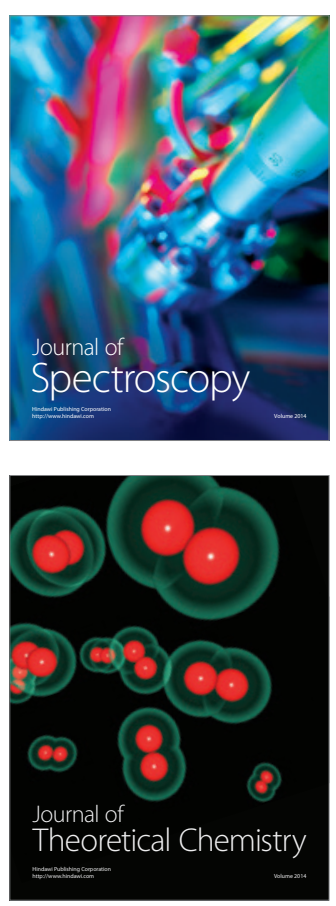
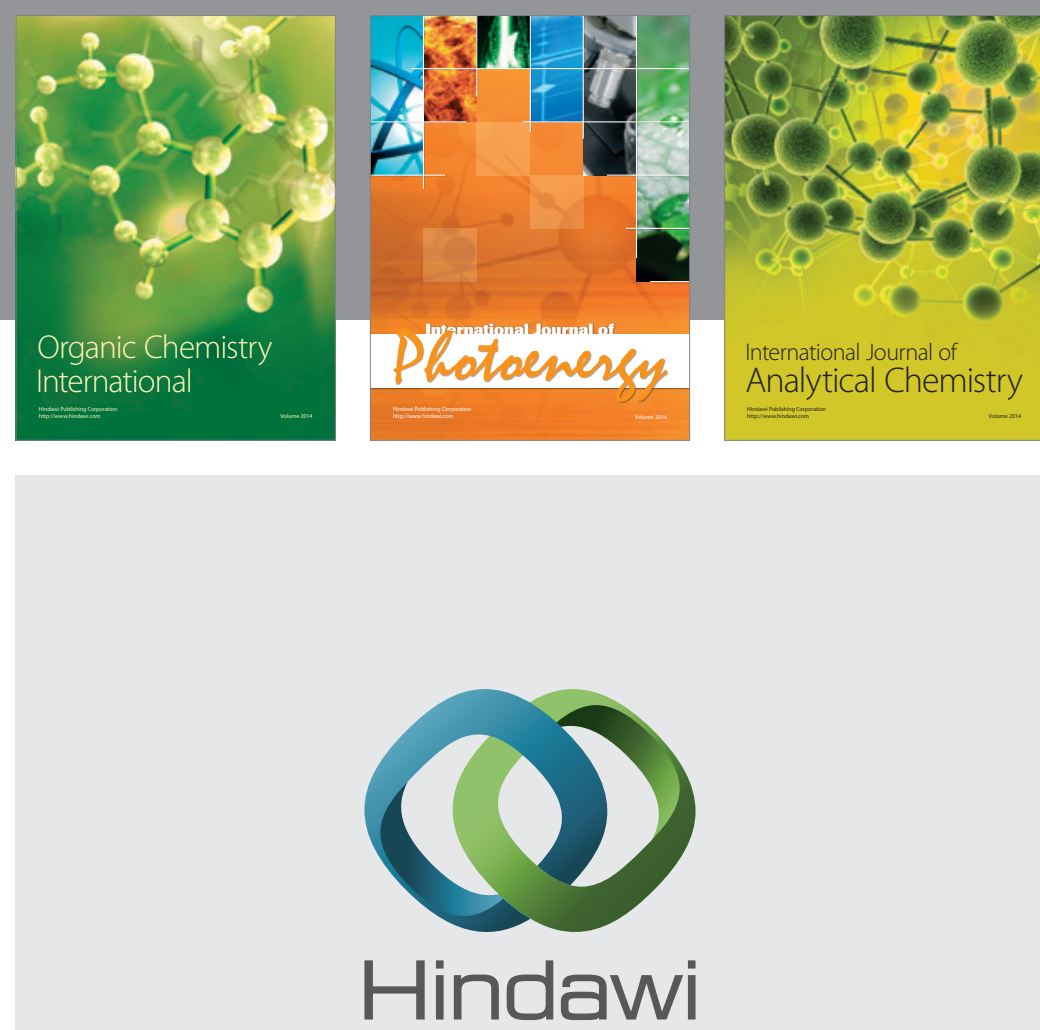

Submit your manuscripts at

http://www.hindawi.com
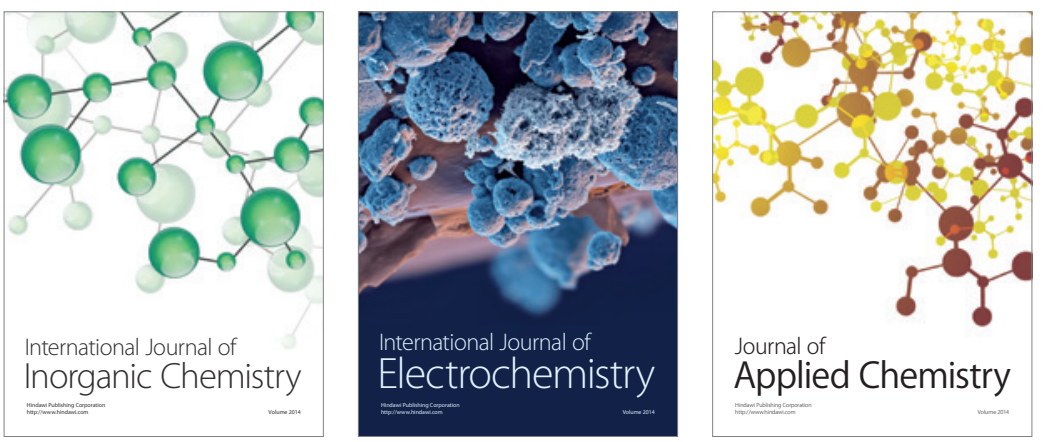

Journal of

Applied Chemistry
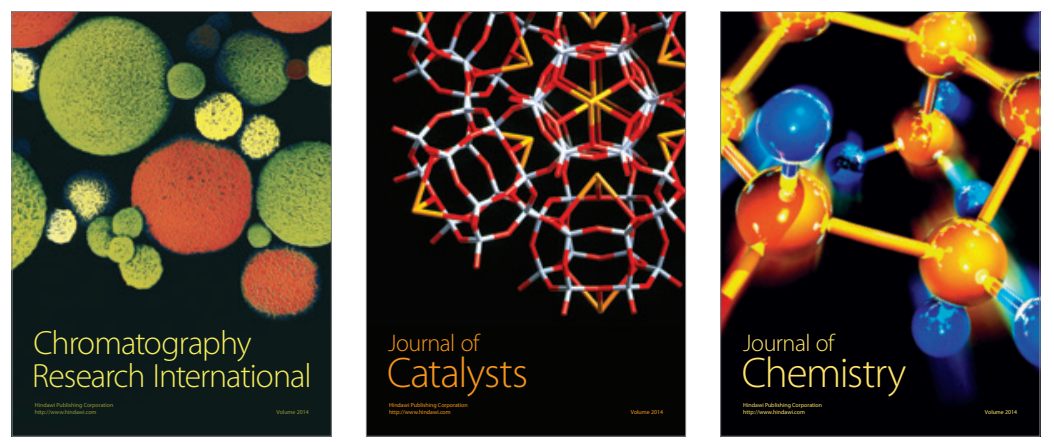
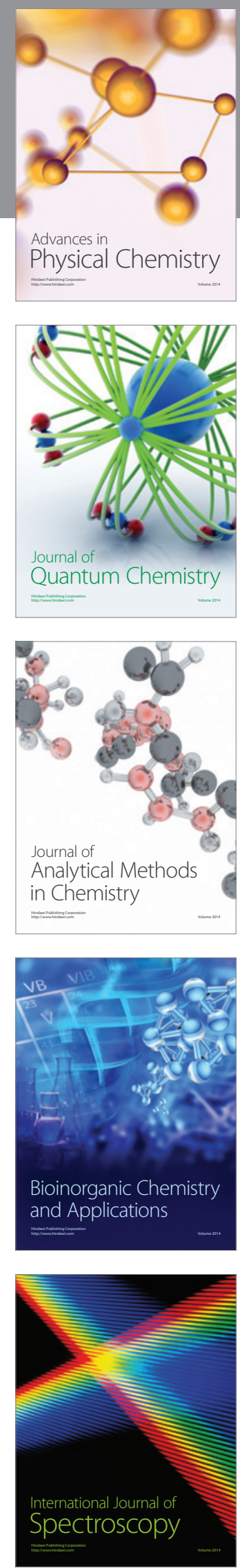